\title{
Experimental studies of the air flow power action on the elements of protective mats
}

\author{
Maria Umahseva*, Yuliya Bryanskaya and Pavel Bazhin \\ Moscow State University of Civil Engineering, Yaroslavskoe shosse, 26, Moscow, 129337, Russia
}

\begin{abstract}
The results of experimental studies to determine the coefficients of aerodynamic resistance in the flow of flexible protective concrete mats located on a horizontal plane are presented. The characteristics of the impact of the power flow on the system of flexible protective mats of various modifications in the aerodynamic laboratory of Moscow State University of Civil Engineering are specified. The experiment was carried out on a subsonic wind tunnel with an open loop using a rigid six-axis force and moment sensor. According to the results of the experiment, it was concluded that the resistance coefficient for the modification of mats with rounding of the upper part of the elements decreases. It has a positive effect on the performance characteristics of this model and increases the lifespan of a structure protected by this modification of coatings.
\end{abstract}

\section{Introduction}

Flexible protective concrete mats are used in the construction of underwater crossings of pipelines, to protect bridge supports, the bottom of the port waters, to strengthen slopes, dumps, and various drainage systems $[4,5,14]$. The design of these protective mats was patented in 1999 [3], but till the present day new modifications of the designs of universal flexible protective coatings are being developed to optimize economic costs and improve performance characteristics for the various needs of the construction industry $[6,18,19]$. However, to date, the issues of changing the hydraulic characteristics of the flow in the zone of location of protective concrete mats with different outlines and parameters of their structural elements have not been investigated.

During airflow, the force interaction between bodies takes place and characteristics of fluid motion in the interaction zone change $[15,17,20]$. When a system of bodies interacts (for example, blocks of a protective mat) with a stream flowing around them, the first row of blocks is directly affected by the oncoming channel flow; the subsequent rows of blocks appear in the tracks formed from the blocks to which the stream flows earlier. As a result, the characteristics of the tracks and the force effect of the flow on the bodies located both in the first and in the subsequent rows change. The bodies located behind the first and subsequent blocks are in the zone of influence of the "deformed" tracks, therefore their

\footnotetext{
Corresponding author: umashevaMA@mgsu.ru
} 
dynamic interaction with the flow is determined by the degree of impact of the blocks on the system of tracks formed behind them.

\section{Materials and methods}

To solve technical problems, when the flow around an obstacle leads to a complex flow pattern that makes theoretical calculation difficult, experimental studies are necessary [13, 16]. As a result of the simulation, it is possible to experimentally establish such characteristics of the interaction of the water flow and the simulated object as pressure loss, distribution of velocity, flow rates and pressures, free surface levels, etc. [8-12]. It is possible to predict the working conditions of objects that have not yet been constructed and to determine their optimal parameters by measuring the values of the model using similarity criteria as a result of the transition from model to nature for similar phenomena.

The hydraulic characteristics of the flow around the protective mat largely depend on the conditions of installation of protective coatings in the working position. In the research, we studied the characteristics of the streams flowing onto the mats installed on the horizontal erosion-resistant bottom of the channel. The article presents the results of studies of the hydrodynamic drag coefficients of two types of flexible protective concrete mats on an aerodynamic stand.

The force effect of the flow on the model is expressed not only in the form of pressure, but also in the form of friction in the boundary layer [7, 12]. In terms of the total effect of the difference in air pressure below and above the model, in front of the model and behind it, as well as from the friction in the boundary layer, the resultant of these forces is formed the total aerodynamic force $\vec{R}[1,2]$ :

$$
R=C_{R} q S
$$

where $C_{R}$ is a coefficient of the total aerodynamic force; $q$ is a dynamic pressure, $q=\frac{\rho v^{2}}{2}$.

In aerodynamic studies, it is convenient to use the force components along the $x, y$, $z$ axes. In the experiment, the $Y$ axis was directed toward the incident flow, $X$ and $Z$ are transverse and vertical axes, respectively (Figure 1).

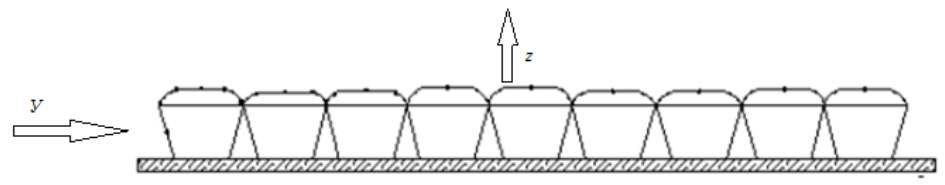

Fig. 1. The scheme of the axes direction

The components of the aerodynamic force coefficient along $C_{X}, C_{Y}, C_{Z}$ coordinate axes depend on the angle of attack and the shape of the body and are determined by models' blow in a wind tunnel.

The wind tunnel Aerolab Educational Wind Tunnel made in the USA (Figure 2) was used to determine the drag coefficients. It was installed in the Educational, Scientific and Production Laboratory for Aerodynamic and Aeroacoustic Testing of Building Structures at the Moscow State University of Civil Engineering.

Aerolab EWT is a subsonic wind tunnel with an open loop. The dimensions of the working chamber are $30.5 \times 30.5 \times 61 \mathrm{~cm}$. The pipe is equipped with a $7.5 \mathrm{~kW}$ ventilator. The flow velocity in the working part of the wind tunnel is from 10 to $65 \mathrm{~m} / \mathrm{s}$. 


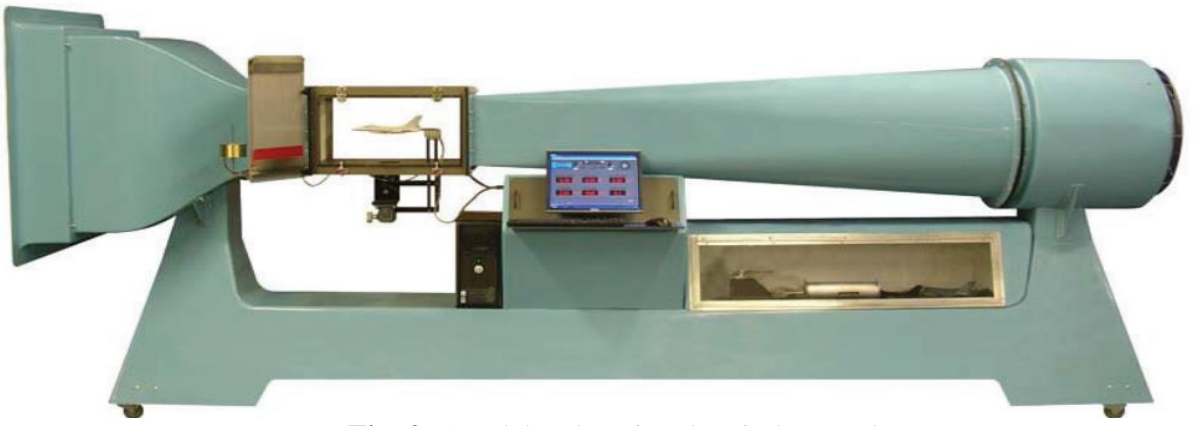

Fig. 2. Aerolab Educational Wind Tunnel

To determine the aerodynamic drag coefficient $C$, models of two types of flexible protective mats were made: UGBZM (Figure 3) and UGBZM-S (Figure 4) at a scale of 1: 8. They were installed in the working chamber of the wind tunnel. The models were fixed on a rigid six-axis force-and-moment sensor FTS-Mini-45 SI-290-10 (Figure 5), which allows obtaining the values of the component of forces and moments developing during the interaction of the flow and the protective mat. An array of experimental data from the sensor was transferred to a computer and recorded.

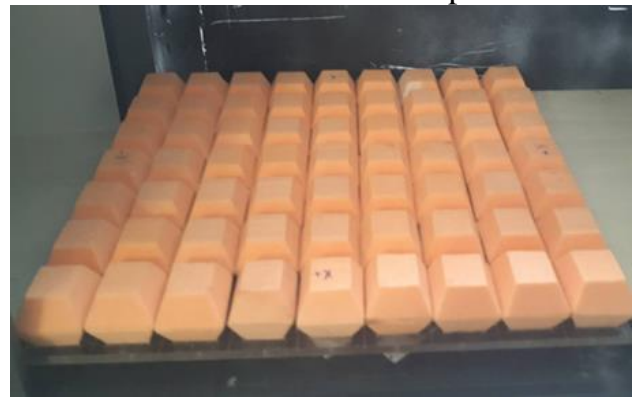

Fig. 3. Experimental model of the mat UGBZM

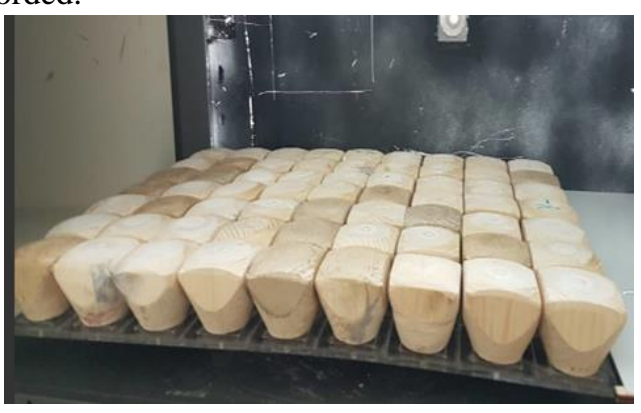

Fig. 4. Experimental model of the mat UGBZM-S

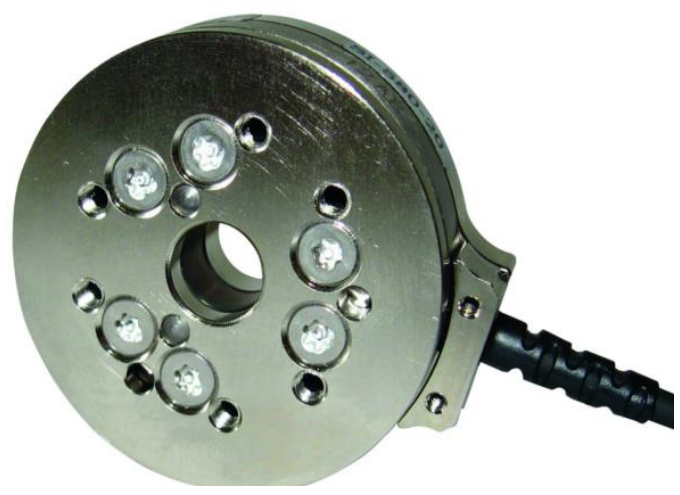

Fig. 5. Force-and-moment sensor 


\section{Results and discussions}

As a result of the measurements, the components of forces and moments along three coordinate axes were obtained. An example of the obtained data on the components of the affecting force from incoming on the mat air at a speed of $8.6 \mathrm{~m} / \mathrm{s}$ for the mat model UGBZM is presented in Table 1, for the UGBZM-S - in Table 2.

Table 1. Indications of forces along three coordinate axes for UGBZM model at $V=8.6 \mathrm{~m} / \mathrm{s}$

\begin{tabular}{|c|r|r|c|c|r|r|r|}
\hline $\begin{array}{c}\text { Time } \\
\text { measurement } \\
\text { number }\end{array}$ & $F_{x}$ & $F_{y}$ & $F_{z}$ & $\begin{array}{c}\text { Time } \\
\text { measurement } \\
\text { number }\end{array}$ & $F_{x}$ & $F_{y}$ & $F_{z}$ \\
\hline 1 & 0,00733 & 0,3563 & 0,53884 & 11 & 0,00844 & 0,35 & 0,49775 \\
\hline 2 & 0,00791 & 0,3615 & 0,54564 & 12 & 0,01114 & 0,3469 & 0,50492 \\
\hline 3 & 0,01124 & 0,3564 & 0,52975 & 13 & 0,00651 & 0,3463 & 0,50578 \\
\hline 4 & 0,01275 & 0,3474 & 0,51348 & 14 & 0,00917 & 0,348 & 0,53078 \\
\hline 5 & 0,00954 & 0,3489 & 0,52938 & 15 & 0,00825 & 0,3556 & 0,50883 \\
\hline 6 & 0,01065 & 0,3489 & 0,50706 & 16 & 0,0118 & 0,3539 & 0,5116 \\
\hline 7 & 0,00755 & 0,3524 & 0,50706 & 17 & 0,01045 & 0,3584 & 0,51353 \\
\hline 8 & 0,00951 & 0,36 & 0,54057 & 18 & 0,00465 & 0,3603 & 0,53237 \\
\hline 9 & 0,00725 & 0,3608 & 0,54275 & 19 & 0,00571 & 0,357 & 0,52792 \\
\hline 10 & 0,00959 & 0,3534 & 0,51758 & 20 & 0,00873 & 0,3526 & 0,50285 \\
\hline
\end{tabular}

Table 2. Indications of forces along three coordinate axes for UGBZM-S model at $V=8.6 \mathrm{~m} / \mathrm{s}$

\begin{tabular}{|c|c|r|r|r|r|r|r|}
\hline $\begin{array}{c}\text { Time } \\
\text { measurement } \\
\text { number }\end{array}$ & $F_{x}$ & $F_{y}$ & $F_{z}$ & $\begin{array}{c}\text { Time } \\
\text { measurement } \\
\text { number }\end{array}$ & $F_{x}$ & $F_{y}$ & $F_{z}$ \\
\hline 1 & 0,05744 & 0,24954 & 0,35587 & 11 & 0,06071 & 0,25786 & 0,34974 \\
\hline 2 & 0,06039 & 0,25276 & 0,35688 & 12 & 0,06537 & 0,25998 & 0,37175 \\
\hline 3 & 0,05995 & 0,25832 & 0,34022 & 13 & 0,06351 & 0,26368 & 0,36418 \\
\hline 4 & 0,05932 & 0,257 & 0,35328 & 14 & 0,06475 & 0,2616 & 0,38239 \\
\hline 5 & 0,06027 & 0,25935 & 0,36473 & 15 & 0,06824 & 0,26937 & 0,3719 \\
\hline 6 & 0,06032 & 0,26054 & 0,36511 & 16 & 0,06276 & 0,26417 & 0,35973 \\
\hline 7 & 0,06298 & 0,26175 & 0,37015 & 17 & 0,06744 & 0,26418 & 0,37275 \\
\hline 8 & 0,06178 & 0,25996 & 0,36815 & 18 & 0,06616 & 0,2642 & 0,36717 \\
\hline 9 & 0,06265 & 0,26819 & 0,38055 & 19 & 0,06484 & 0,25934 & 0,35263 \\
\hline 10 & 0,06447 & 0,26665 & 0,37742 & 20 & 0,06562 & 0,25694 & 0,35316 \\
\hline
\end{tabular}

The experimental values of the resistance coefficient of the concrete mat were determined by the formula [7]:

$$
C_{D}=\frac{2 F_{c}}{\rho u^{2} s} .
$$

The calculations of the hydrodynamic resistance coefficient for the UGBZM model are given in Table 3, for the UGBZM-S model - in Table 4.

To determine the drag coefficients along various flow direction axes, the model areas were used without calculating the gaps between them. The calculation was made according to the following method: for UGBZM mats, the area of one model cube was determined $\left(S=0.0009187 \mathrm{~m}^{2}\right)$. 
Table 3. Drag coefficients for UGBZM model at $V=8.6 \mathrm{~m} / \mathrm{s}$

\begin{tabular}{|c|c|c|c|c|c|c|c|}
\hline $\begin{array}{c}\text { Time } \\
\text { measurement } \\
\text { number }\end{array}$ & $C_{x}$ & $C_{y}$ & $C z$ & $\begin{array}{c}\text { Time } \\
\text { measurement } \\
\text { number }\end{array}$ & $C_{x}$ & $C_{y}$ & $C z$ \\
\hline 1 & 0,019983 & 1,47833 & 0,120462 & 11 & 0,022994 & 1,45246 & 0,111277 \\
\hline 2 & 0,021547 & 1,5001 & 0,121981 & 12 & 0,030359 & 1,43959 & 0,112878 \\
\hline 3 & 0,030628 & 1,47891 & 0,11843 & 13 & 0,017737 & 1,43706 & 0,113071 \\
\hline 4 & 0,034744 & 1,44133 & 0,114792 & 14 & 0,024984 & 1,44402 & 0,11866 \\
\hline 5 & 0,026009 & 1,44778 & 0,118347 & 15 & 0,022482 & 1,47571 & 0,113753 \\
\hline 6 & 0,029029 & 1,44772 & 0,113357 & 16 & 0,03216 & 1,46865 & 0,114372 \\
\hline 7 & 0,020572 & 1,46219 & 0,113357 & 17 & 0,028467 & 1,48707 & 0,114804 \\
\hline 8 & 0,025919 & 1,49365 & 0,12085 & 18 & 0,012665 & 1,49516 & 0,119017 \\
\hline 9 & 0,019751 & 1,49693 & 0,121336 & 19 & 0,015551 & 1,4812 & 0,11802 \\
\hline 10 & 0,026134 & 1,46658 & 0,115708 & 20 & 0,02379 & 1,4629 & 0,112416 \\
\hline
\end{tabular}

Table 4. Drag coefficients for UGBZM-S model at $V=8.6 \mathrm{~m} / \mathrm{s}$

\begin{tabular}{|c|c|c|c|c|c|c|c|}
\hline $\begin{array}{c}\text { Time } \\
\text { measurement } \\
\text { number }\end{array}$ & $C_{x}$ & $C_{y}$ & $C \mathrm{z}$ & $\begin{array}{c}\text { Time } \\
\text { measurement } \\
\text { number }\end{array}$ & $C_{x}$ & $C_{y}$ & $C \mathrm{z}$ \\
\hline 1 & 0,208325 & 1,163602 & 0,101871 & 11 & 0,220174 & 1,202399 & 0,100116 \\
\hline 2 & 0,21902 & 1,178612 & 0,102161 & 12 & 0,237075 & 1,212284 & 0,106416 \\
\hline 3 & 0,217425 & 1,204581 & 0,09739 & 13 & 0,230322 & 1,229538 & 0,104249 \\
\hline 4 & 0,215143 & 1,198398 & 0,10113 & 14 & 0,234833 & 1,219853 & 0,109463 \\
\hline 5 & 0,218574 & 1,209375 & 0,104409 & 15 & 0,247491 & 1,256075 & 0,106461 \\
\hline 6 & 0,218763 & 1,214919 & 0,104516 & 16 & 0,227627 & 1,231841 & 0,102978 \\
\hline 7 & 0,228407 & 1,220552 & 0,105959 & 17 & 0,244582 & 1,231893 & 0,106704 \\
\hline 8 & 0,224047 & 1,212191 & 0,105386 & 18 & 0,239951 & 1,231981 & 0,105106 \\
\hline 9 & 0,227203 & 1,250601 & 0,108935 & 19 & 0,235163 & 1,209328 & 0,100943 \\
\hline 10 & 0,233807 & 1,243424 & 0,10804 & 20 & 0,238 & 1,198109 & 0,101095 \\
\hline
\end{tabular}

To determine the area of the model along the $X$ axis, the lateral surface area of one cube was multiplied by the number of cubes in the mat model along a given axis ( 9 pieces). The resulting total area $S_{X}=0.0082683 \mathrm{~m}^{2}$.

Along the $Y$ axis, the area of the midsection section of the cube was multiplied by 7 (by the number of elements in the direction). The resulting total area $S_{Y}=0.0064309 \mathrm{~m}^{2}$.

For calculating the drag coefficient along the $Z$ axis was taken the area of the upper surface of the experimental model of the mat was chosen. It was calculated by the rectangle area formula $\left(S_{Z}=0.1008 \mathrm{~m}^{2}\right)$.

Area calculations for UGBZM-S model were carried out according to the same method as for UGBZM model and were respectively: $S_{X}=0.007956 \mathrm{~m}^{2}, S_{Y}=0.006188 \mathrm{~m}^{2}, S_{Z}=$ $0.1008 \mathrm{~m}^{2}$.

From experimental data, it is clear that the greatest force was along the $Z$ axis. This component of the force is a lifting force for the design model. The data obtained along the $Y$ axis significantly exceed the values of the force along the $X$ axis, since the flow ran along the $Y$ axis, and the data obtained along this axis is the force of drag to the incoming air. The data on the $X$ axis is minimal for mats of any modification, since in this experiment, the force $F_{x}$ was transverse to the direction of flow, and the model is symmetrical in the direction of flow and, therefore, the transverse force tends to zero. To calculate the 
resistance coefficient of the model, the resistance force along the $Y$ axis was taken into account.

In total, three series of experiments were carried out on each model of the protective mat in the following speed modes:

- $20 \%$ of ventilator power at which the velocity was $8.6 \mathrm{~m} / \mathrm{s}$;

- $40 \%$ of ventilator power at which the velocity was $16.7 \mathrm{~m} / \mathrm{s}$;

- $60 \%$ of ventilator power at which the velocity was $20.0 \mathrm{~m} / \mathrm{s}$.

According to the formula (2), the aerodynamic drag coefficient for UGBZM model $C_{D}$ $=1.466$, for UGBZM-S $C_{D}=1.023$. The experimental data are consistent with the previously obtained values for the drag coefficients of similar experimental forms.

\section{Discussions and conclusions}

As a result of the experimental studies, the values of the aerodynamic drag coefficients for two modifications of flexible protective concrete coatings were obtained. Based on the obtained calculations, it can be concluded that the drag coefficient decreases at the air flow rate of $8.6 \mathrm{~m} / \mathrm{s}$ for UGBZM-S model of mats. According to the experimental data, the coefficients of the lifting force were also calculated. It gives an opportunity to calculate the anchorage of the coatings and their stability with respect to the incoming air more correctly.

\section{References}

1. Savitsky G.A. (1972). Wind load on buildings, Moscow.

2. Phabrikant N.Ya. (1964). Aerodynamics. General course, Moscow.

3. Patent No. 2129635 of April 27, 1999.

4. Specifications TU 5859-001-35842586-2009 LLC "Micron B" "Mats concrete protective flexible universal UZGBM.

5. Specifications TU 5859-001-35842586-2009 LLC "Micron B" "Mats concrete protective flexible universal UZGBM-S.

6. Lemeshko M.A., and Savchenko D.V. (2018). Shore-strengthening hydraulic structures in the form of flexible concrete mats. Collection of studies. Moscow, 272-277.

7. Bogomolov A.I., Borovkov V.S., and Mayranovsky F.G. (1979). High-speed flows with a free surface. M0scow, 344.

8. Mostkov M.A. (1959). Sketch of the theory of channel flow. Moscow, 246.

9. Zuykov A.L. (2014). Hydraulics. Textbook in 2 volumes. Volume 1. Basics of fluid mechanics. Moscow, 1, 518.

10. Shterenlicht D.V. (2004). Hydraulics. Moscow, 656.

11. Kiselev P.G. (1980). Hydraulics. Fundamentals of fluid mechanics. Moscow, 360.

12. Schlichting G. (1969). Theory of the boundary layer. Moscow, 742.

13. Yumasheva M.A., and Bryanskaya Yu.V. (2018). Experimental studies of the velocity characteristics of the flow in its interaction with flexible protective coatings. In Gidrotekhnicheskoye stroitel'stvo. 10, 6-10.

14. Yumasheva M.A., and Bryanskaya Yu.V. (2016). The use of flexible concrete protective coatings for construction on water bodies. In Construction - formation of environment. Moscow, 1106-1109.

15. Bryanskaya Yu.V., Borovkov V.S., Rylova I.A., and Yumasheva M.A. (2016). Hydraulic characteristics of the flow around the protective concrete mats. In Gidrotekhnicheskoye stroitel'stvo. 10, 132-137. 
16. Yumasheva M.A., and Bryanskaya Yu.V. (2016). Methods and techniques for experimental studies of the hydraulic characteristics of the stream flowing around flexible concrete pavements. In Nauchnoye obozreniye. 20, 19-24.

17. Borovkov V.S., Bryansky I.A., and Yumasheva M.A. (2017). Features of the transverse flow of water bodies of various shapes in the presence of the screen. In Nauchnoye obozreniye. 6, 27-33.

18. Bainatov ZH.B., and Doskhodaev A.S. (1991). Effective constructions of protective coatings against erosion. In Express-inform. 2.

19. Kozlov K. D., Guriev A.P., and Khanov N.V. (2014). Hydraulic studies of the coating of geocomposite material. In Environmental Engineering. 5, 80-86.

20. Kozlov K.D., Khanov N.V., Fartukov V.A., and Kozlov D.V. (2018). Studies of the hydrodynamic effects of flow on a protective coating of geosynthetic material. In Construction: science and education. 8, 1 (27), 108-117. 